\title{
IMPLEMENTANDO A PARTICIPAÇÃO PÚBLICA NO BRASIL: Sociologia de atores secundários ${ }^{1}$
}

\author{
Marie-Hélène Sa Vilas Boas*
}

\begin{abstract}
As instituições participativas brasileiras foram analisadas por uma densa literatura que estudou os projetos subjacentes a essas mesmas instituições, o engajamento dos cidadãos e os efeitos variáveis da participação sobre o campo político. Porém, a literatura pouco questionou o papel dos profissionais da participação, ou seja a atuação dos atores específicos que são pagos para conceber, organizar e facilitar as instituições participativas. Este artigo, baseado numa metodologia qualitativa, propõe uma tipologia dos organizadores das instituições participativas no Brasil. A hipótese desenvolvida é que esses atores têm um papel fundamental na delimitação do que significa participar e dos públicos legítimos nas instituições participativas. Ao privilegiar certos perfis de cidadãos, algumas ferramentas ou alguns comportamentos sobre outros, estes atores podem dar às instituições participativas um escopo transformador ou pelo contrário, defini-los como uma simples consulta dos cidadãos.
\end{abstract}

PALAVRAS Chave: Participação pública. Brasil. Burocratas. Profissionalização. Tipologia.

Quem são os atores que implementam a participação pública no Brasil e que influência eles têm nas instituições participativas (IPs)? Uma vasta literatura, principalmente realizada sobre as IPs locais, apontou três elementos para compreender o seu funcionamento e os efeitos diferenciados sobre a ação pública e política (Avritzer; Navarro, 2003; Borba; Lüchmann, 2007). Primeiro, os “projetos" perseguidos pelos governos foram associados a valorização de certa concepção das relação políticas e sócio-econômicas e, portanto, certos segmentos da população convidados a participar na definição das políticas públicas. Nesta perspectiva, o projeto de "inclusão dos excluídos" defendido pelo Partido dos Trabalhadores (PT) foi visto, até o inicio dos anos 2000, como um dos fatores explicativos do envolvimento de atores tra-

\footnotetext{
* Universidade Côte d'Azur. Bureau 420 bis. Faculté de Droit et Science politique.

Avenue du Doyen Trotabas, 06000. Nice - France.

Marie-helene.sa-vilas-boas@univ-cotedazur.fr https://orcid.org/0000-0003-0968-3007

${ }^{1}$ Este artigo foi traduzido por Wagner Romão, que a autora agradece sinceramente.

A autora agradece os coordenadores pelos comentários e as revisões do artigo. Todos os erros permanecendo são da responsabilidade da autora.
}

dicionalmente sub-representados nas IPs bem sucedidas. Segundo, autores mostraram que o desenho institucional dos espaços participativos, por ser a materialização dos projetos políticos, enquadram as formas de investimento nos espaços participativos e a influência que esses espaços têm na ação publica. Terceiro, os efeitos das IPs foram estudados à luz da configuração da sociedade civil, ou seja a capacidade de mobilização das organizações civis e a sua ação coordenada. O sucesso de Porto Alegre é assim pensado como resultado desses elementos, ou seja, um projeto voluntarista de mudança social, uma tradição associativa forte e um design que garante o envolvimento de atores tradicionalmente ausentes e que lhes dão certo poder decisório (Avritzer, 2009).

Esses três fatores explicativos alimentaram uma série de estudos comparativos que aprofundaram a nossa compreensão das IPs. Porém, eles dão pouca atenção à atuação de atores que no entanto são centrais na concepção e no funcionamentos das instituições participativas, ou seja os burocratas ou atores externos à administração contratados para desenhar, implementar ou facilitar espaços parti- 
cipativos, chamados por parte da literatura de "profissionais de participação pública" (PPP). Este artigo tem como objetivo estudar o perfil e as práticas desse atores nas IPs brasileiras. A hipótese desenvolvida neste texto é que estes PPP, ao organizar o cotidiano dessas instituições, têm um papel fundamental na delimitação do que significa participar. Com efeito, ao privilegiar certos perfis de cidadãos, algumas ferramentas ou alguns comportamentos sobre outros, estes atores podem reforçar o escopo transformador das instituições participativas ou, pelo contrário, restringi-los a uma mera consulta dos cidadãos.

A atuação dos PPP deve então ser tomada em consideração se quisermos compreender a variação dos efeitos das instituições participativas e as evolução no campo da participação pública. Mas para compreender as práticas desses atores, é necessário articular uma dupla perspectiva. A primeira concentra-se na trajetória desses atores, para identificar quais valores e saberes eles trazem às instituições participativas dependendo da trajetória, militante ou profissional, que eles têm. Mas esta perspectiva centrada nos atores seria incompleta se ela não fosse ligada a um estudo das lógicas institucionais que enquadram as práticas dos PPP. Dito de outro modo, para analisar o papel dos PPP, é preciso articular um estudo do perfil dos atores que organizam a participação cidadã com uma análise dos contextos จิ institucionais nos quais atuam.

A partir desta dupla abordagem, este artigo desenvolve uma tipologia dos organizadores de algumas IPs brasileiras. Ele se baseia no $\stackrel{\infty}{\rightarrow}$ estudo de diferentes tipos de PPP que conheci $\dot{2}$ em duas pesquisas. A primeira é uma tese de doutorado sobre a mobilização de moradores de base nas conferências de mulheres de Recife e Londrina, para a qual realizei um trabalho de campo de dois anos. Inclui um estágio de seis meses em 2006 na administração responsável pela IP, a Coordenadoria da Mulher do Recife. Em Londrina, fiz uma observação etnográfica de sete meses em 2007. Também realizei 32 en- trevistas com participantes e administradores locais em Recife e $25 \mathrm{com}$ atores semelhantes em Londrina. A segunda pesquisa, realizada em 2014 e 2015, teve como objetivo compreender a difusão de ferramentas digitais no campo participativo brasileiro no Brasil, com foco no caso de Belo Horizonte, onde fiz seis entrevistas com os organizadores do Orçamento Participativo Digital e fiz um mês de observação.

Após uma revisão da literatura que detalha os desafios teóricos da análise dos organizadores das instituições participativas, o texto propõe distinguir três tipos de PPP: o "burocrata militante", o "profissional da mobilização" e o "profissional especialista". A trajetória e as práticas de cada um desses PPP estão ligadas a experiências específicas, ou seja, conferências de mulheres do Recife para o primeiro tipo, várias conferências municipais em Londrina para o segundo e Orçamento Participativo Digital de Belo Horizonte para o terceiro tipo. Esta apresentação visa destacar as semelhanças e diferenças entre os três tipos de PPP. Mas isso claramente simplifica a realidade. De fato, podemos encontrar cada tipo de PPP nas três cidades, embora em proporções diferentes e com influência desigual. Portanto, os perfis descritos neste artigo correspondem aos tipos ideais e não à expressão de diferenças específicas entre as três cidades.

\section{ENTRE TRAJETÓRIAS INDIVIDUAIS E CONTEXTOS INSTITUCIONAIS: estudar os "profissionais" da parti- cipacão}

O estudo dos organizadores da participação cidadã seguiu rumos diferentes no caso das experiências europeias e norte-americanas por um lado, e por outro lado, das brasileiras. Essas diferenças dependem dos contextos político-institucionais de criação das IPs assim como de questionamento distintos aplicados à participação cidadã. 


\section{Organizar a participação cidadã: uma profissão?}

Na Europa e na América do Norte, um campo de estudo se desenvolveu recentemente sobre os atores chamados public participation professionals (PPP) ou "profissionais de participação pública” por Laurence Bherer, Mario Gauthier e Louis Simard a partir de uma perspectiva comparada entre países destas mesmas zonas geográficas (Bherer; Gauthier; Simard, 2017a). Desta perspectiva, PPP são vistos como "formando parte de uma nova profissão política que tem sido desenvolvida nos últimos 20 anos e que tem assumido uma crescente importância em atividades de mobilização e influência política” (Ibid., p. 6). Pesquisadores apontam as dificuldades de analisá-los por causa de seu perfil diverso, o que inclui militantes, profissionais da comunicação ou servidores públicos, apenas para mencionar alguns deles, agindo na esfera pública ou privada (Mazeaud; Nonjon, 2018). Devido a essa diversidade, estes atores não respondem ao conceito exato de profissão, se este termo definir um grupo que defende "o monopólio do exercício de um trabalho pelo controle do conteúdo das habilidades relativas a ele, sua transmissão e a socialização de seus membros, as regras de ética que regem sua implementação, o valor social e econômico de sua atividade" (Demazière, 2009, p. 84). Porém, como Didier Demazière e Charles Gadéa (2009) sublinham, esta definição é bastante restrita e apenas corresponde a profissões bastante específicas no topo de uma hierarquia ocupacional, caracterizada por um alto nível de expertise e uma relevante autonomia na performance no trabalho. A noção de "grupo profissional" tem sido desenvolvida (Chapoulie, 1973), para estudar outro tipo de trabalhadores, em particular em atividades pouco qualificadas ou com baixa qualificação, como trabalhos artísticos ou de voluntariado. Ademais, os processos de descentralização, de contratualização e de transversalidade que guiam a ação pública em vários países da Europa levaram à emergência do que Gilles Jeannot chama de "profissões vagas" (métiers flous) cuja missão é confusa e cujo estatuto pode ser diverso, tais como os profissionais da participação cidadã. Segundo Jeannot (2005), o caráter vago destas profissões depende diretamente da complexidade da ação pública e da multiplicidade dos objetivos perseguidos e atores envolvidos em alguns setores de políticas públicas.

Com este referencial analítico, a noção de profissionalização começou a ganhar importância e passou a ser utilizada para se compreender processos de criação, diferenciação e empoderamento de diversas atividades profissionais. Desta perspectiva, profissionalização não é vista como um processo linear porque ela frequentemente repousa em dinâmicas ambíguas e até contraditórias de delimitação e erosão de um grupo, de legitimação e negação de sua existência etc. (Demazière, 2009).

Se a relevância do conceito de profissionalização foi discutida na sociologia do trabalho (Becker, 1962; Boussard et. al., 2010) bem como na sociologia política (Michon; Ollion, 2018), pode ser um conceito útil quando usado para analisar um processo duplo que caracteriza "atividades políticas periféricas" (Gaxie, 2001, p. 23), o qual inclui a implementação de IPs. Tal processo diz respeito 1) ao fato de que alguns atores a partir de agora vivem da democracia participativa, embora nem sempre seja sua atividade ou fonte de renda única; ${ }^{2}$ 2) à consolidação de habilidades e conhecimentos específicos sobre democracia participativa, aprendidos em treinamentos específicos ou através de um processo de socialização em esferas sociais / profissionais específicas.

Nos contextos norte-americano e europeu, os estudiosos mostraram como pode ser heurístico estudar quem são esses profissionais, a fim de entender como eles moldam o campo participativo usando alguns procedi${ }^{2}$ Refiro-me à famosa distinção de Weber sobre políticos profissionais que vivem "da” e "para” a política. Mas, como sublinhado por Mazeaud e Nonjon (2018, p. 10), é difícil aplicar esta definição aos PPP pois, para alguns deles, participação pública não é sua principal fonte de renda; outros atuam na participação mas mantém certa distância dos ideais da democracia participativa, ou seja, não vivem realmente "para" a participação pública. 
mentos em vez de outros, definindo as normas legítimas de conduta dentro das IPs ou promovendo determinadas concepções e práticas. Dependendo do país estudado, os PPP não designam o mesmo tipo de atores. Nos EUA e no Canadá, são principalmente atores privados, ONGs ou empresas contratadas por instituições públicas (Lee, 2017, Bherer; Gauthier; Simard, 2017b), enquanto no Reino Unido atuam tanto em instituições públicas quanto em estruturas privadas (Escobar, 2017). Além disso, dependendo da forma como eles modelam e materializam os dispositivos participativos, o PPP pode dar-lhes significados que não necessariamente respondem aos ideais participativos. Nos EUA, Caroline Lee e Zachary Romano (2013) mostram que os PPP vendem democracia participativa a instituições públicas, a fim de fazer o cidadão aceitar "escolhas difíceis”, como a austeridade. Na França, Alice Mazeaud e Magali Nonjon (2018) destacam o surgimento de um efeito de "mercado participativo" que atua na padronização de IPs.

Estes estudos apontam então a necessidade de compreender as IPs tomando em consideração os atores - secundários na hierarquia politica e administrativa - que os organizam a partir de dois eixos: primeiro, os saberes e concepções profissionais que eles trazem às instituições participativas; segundo, as lógicas que guiam a sua ação e que dependem do quadro institucional.

\section{Dentro da lógica administrativa brasileira}

A reflexão seguiu rumos diferentes em volta das IPs brasileiras. Raros são os trabalhos que questionaram o perfil e a influência dos organizadores das IPs sobre as lógicas internas de funcionamento destas mesmas instituições. Porém, as análises feitas sobre a percepção que os burocratas têm das IPS e sobre a relação que eles entretêm com as organizações da sociedade civil, pelo meio de IPs ou não, apontam elementos interessantes para compreender como atuam os PPP. Primeiro, Jessica Rich (2019a, 2019b) mostra que a atuação dos burocratas é central nos espaços participativos, em particular porque eles podem dar recursos, informacionais, financeiros ou simbólicos, mais ou menos importantes às organizações da sociedade civil e desta forma contribuir ao reforço ou ao enfraquecimento da ação coletiva nas IPs. Em contrapartida, a presença de uma sociedade civil mobilizada pode dar mais peso a uma administração quando negocia uma política pública com outras (Sa Vilas Boas, 2019). Segundo, Clóvis de Souza e Roberto Pires (2012) mostram a diversidade de motivações e de investimentos das IPs pelos burocratas. Além dos objetivos e projetos exibidos pelos atores políticos, os burocratas dão sentidos múltiplos a essas instituições, que dependem em parte das lógicas institucionais nas quais atuam. Como os trabalhos de Jeannot, esse estudo mostra a importância de compreender a configuração na qual os burocratas agem quando criam e implementam uma IP. Terceiro, esses mesmos burocratas defendem valores e concepções distintos de um tema, quer seja o meio ambiente, a saúde ou a gestão urbana, dependendo dos vínculos que eles tiveram ou não com organizações do movimento social, mas também das normas próprias da administração na qual atuam (Abers, 2019; 2015) . Observamos então que alguns podem ser qualificados de "burocratas ativistas" devido à maneira como eles defendem uma causa dentro das instituições públicas (Abers, 2019).

Esses estudos nos ajudam a pensar o papel dos PPP de duas maneiras. Primeiro, apontam a necessidade de compreender o comportamento dos burocratas à luz das relações de poder dentro da administração publica e não só dos projetos políticos defendidos pelos eleitos e partidos políticos. Segundo, convidam a compreender os valores e concepções que os burocratas mobilizam nas suas práticas profissionais, dependo da trajetória que eles têm e da cultura administrativa da qual fazem parte. Porém, esses estudos não questionam propriamente a influência que os burocratas têm sobre o funcionamento inter- 
no das IPs e a sua composição. É essa questão que vamos agora desenvolver a partir da análise de três tipos-ideais de PPP.

\section{O BUROCRATA MILITANTE}

O primeiro tipo de PPP pode ser chamado de "burocratas militantes" porque sua ação se baseia na importação de práticas militantes em uma IP que eles concebem e organizam. Os burocratas militantes dependem principalmente do conhecimento aprendido na esfera partidária ou militante. Eles vinculam as IPs às normas e práticas da ação coletiva: valorizam o empoderamento dos participantes e um engajamento contínuo. Eles são os menos profissionalizados de nossa tipologia, na medida em que não dependem de ferramentas e práticas desenvolvidas especificamente para as IPs, nem de conhecimento especializado. Esses atores estão no centro de novos espaços participativos em alguns setores de políticas públicas, ou seja, nas quais as organizações da sociedade civil desempenham um papel central na definição da agenda ou na implementação de políticas. Os responsáveis pela conferência das mulheres em Recife são ilustrativos desse primeiro tipo de PPP.

\section{Democracia participativa como projeto político}

"Burocratas militantes" correspondem aos atores que organizam, facilitam e/ou avaliam uma IP como parte de sua atividade político-administrativa. Eles não eram especializados em participação pública antes de serem recrutados pelo governo local e não trabalham apenas nisso. Mas a valorizam devido à sua trajetória militante. Para esse tipo de ator, a participação pública é uma maneira de colocar em prática as idéias defendidas na esfera militante e manter fortes os laços com organizações da sociedade civil. Portanto, para eles, o objetivo da participação pública não é necessaria- mente reunir todos os habitantes, mas dar voz a alguns deles, seja porque o governo local os valoriza, seja porque são vistos como "aliados" de sua administração. Para esse tipo de ator, a participação pública é uma maneira de executar um projeto político específico e não alcançar um consenso entre pontos de vista muito diferentes, como é o caso dos PPP em torno do Bureau d'Audiences Publiques sur l'Environnement (BAPE) em Québec (Bherer; Gauthier; Simard, 2017b) ou da Commission Nationale $d u$ Débat Public (CNDP) na França (Revel et. al., 2007). Eles defendem um projeto transformador, que visa mudar as relações sociais, incluindo grupos minoritários, e politizá-los.

Esse tipo de ator é predominante nas conferências das mulheres em Recife, cujo desenho foi definido pela Coordenadoria da Mulher, criada em 2001 após a eleição de João Paulo, do Partido dos Trabalhadores (PT), à prefeitura. No início de 2000, poucas cidades brasileiras haviam implementado conferências de mulheres; portanto, sua criação no Recife é uma inovação. De fato, ela mescla três tipos de procedimentos usados em vários espaços participativos: aqueles do orçamento participativo, especialmente o princípio de uma primeira rodada de assembléias nos bairros; as regras das conferências tradicionais, especialmente a representação das organizações da sociedade civil; e a criação de um conselho de política pública, cujos membros são eleitos durante as assembléias.

Esse desenho não pode ser compreendido sem se analisar o perfil da equipe da Coordenadoria da Mulher. Esta administração pública faz parte do Gabinete do Prefeito e seus membros são indicados pelo governo de coalizão. Devido a esse modo específico de designação, o perfil de nomeados para a Coordenadoria da Mulher é menos burocrático do que partidário. De fato, o perfil delas é bastante homogêneo. Cinco das seis indicadas eram ativistas de um partido da coalizão do governo, sendo que três delas pertenciam ao PT. Elas também foram ativistas de uma organização feminista e participaram do encontro da principal rede 
de organizações de mulheres, a Federação das Mulheres de Pernambuco (FMPE).

Esse perfil ativista estrutura os procedimentos de participação realizados na Conferência de Mulheres. Primeiro, reproduz o que na época era visto como o "modo petista de governar"; segundo, dá um papel importante às organizações feministas.

É com base na experiência de outros governos do PT que a equipe da Coordenadoria da Mulher define o desenho da conferência das mulheres. A pessoa encarregada pela participação na Secretaria explica:

J: "Antes de sermos eleitos, não tínhamos uma ideia clara do que faríamos. Tudo foi definido após a eleição. Mas claro que vínhamos de um partido para o qual a democracia é uma questão de todos. Para quem as políticas de gênero devem incluir todas e todos e também o movimento das mulheres. [...] Nós [mulheres do Partido dos Trabalhadores] participamos da definição do programa eleitoral, mas tudo foi muito geral. Foi somente depois da eleição que começamos a pensar no que poderíamos fazer. Obviamente, queríamos criar um espaço de participação, mas não tínhamos ideia de como e o que poderíamos fazer. Então, depois do primeiro turno, quando entendemos que poderíamos vencer as eleições, pedimos que Regina, que na época era a Secretária das Mulheres no Rio Grande do Sul, viesse aqui. Fizemos um seminário em que ela explicou o que estavam fazendo no sul. Elas não tinham conferências de mulheres, mas estavam organizando reuniões com mulheres em diferentes territórios e sobre diferentes temas. Então, levamos esse modelo para a conferência. E ela nos disse: 'se você puder consultar as mulheres para saber o que elas querem, será mais fácil definir suas prioridades'. E foi o que fizemos”. (Entrevista com J., membro da Coordenadoria da Mulher, 26 de março de 2006).

A importação de ferramentas elaboradas pelo PT em outros territórios acompanha a reprodução de uma certa concepção do público chamado a participar. Embora a conferência tenha como objetivo reunir as mulheres da cidade, algumas são favorecidas, principalmente as das classes mais baixas, de maneira a ajustar a conferência das mulheres ao discurso classista do partido. Segundo a Secretária geral responsável em 2001:

“A: Quando a Secretaria de Mulheres foi criada, houve muitos debates sobre a necessidade de criar essa estrutura. Alguns acreditavam que um setor encarregado de todos os tipos de discriminação seria melhor. Na realidade, esses debates mostraram que as questões de gênero não tinham legitimidade [...]. Quando falamos em criar uma conferência de mulheres, todos nos disseram: 'calma, não se apresse, tudo é novo’. Mas para nós não era uma discussão e queríamos apoio. Encontramos o Secretário geral de orçamento participativo e contamos a ele nossos planos. Ele disse que o convencemos quando dissemos que queríamos introduzir o feminismo na classe trabalhadora. Porque o feminismo não pode ser um assunto apenas da classe média”.

(Entrevista com A., ex-Secretária da Coordenadoria da Mulher, 31 de janeiro de 2007).

O foco na classe social determina parcialmente o desenho da conferência, especialmente a primeira rodada de assembléias em bairros populares. Esses procedimentos devem ajudar a incluir atores "inaudíveis", devido à dominação de classe e gênero, mas também a despertar mulheres pobres para o feminismo. Este segundo objetivo justifica a posição específica conferida às organizações feministas na conferência, em particular a algumas delas, consideradas "aliadas" da Coordenadoria da Mulher devido ao projeto comum de subverter a ordem de gênero. Portanto, as regras da conferência garantem a presença de um tipo específico de organização feminista, que corresponde ao FMPE e seus coletivos membros. Paralelamente, alguns atores e organizações são "esquecidos" ou discretamente deixados de lado, especialmente aqueles considerados conservadores em questões de gênero, como movimentos religiosos ou departamentos femininos de partidos de direita.

\section{Democracia participativa como extensão da ação coletiva}

Para burocratas militantes, a democracia participativa é uma maneira de reconciliar sua trajetória ativista, que influencia profundamente sua autopercepção, e sua nova posição como indicado pelo governo local. Quan- 
do elas têm uma trajetória de ativismo em um partido e uma organização feminista, a entrada no Estado gera sentimentos ambivalentes. Por um lado, sua indicação é percebida como uma retribuição específica e reconhecimento de seu ativismo. Ao contrário dos servidores públicos que ingressam na administração local após serem aprovados em um concurso, em parte elas devem sua posição aos "camaradas" eleitos e sentem-se investidos de uma missão coletiva na defesa do projeto construído coletivamente. Por outro lado, elas estão doravante do "outro lado da cerca” e essa posição altera a relação que eles têm com ativistas que em muitos casos eram amigos ou amigas. Por exemplo, uma indicada descreve as dificuldades que teve em assumir a posição de "representante do governo local":

J: "Durante a primeira conferência, tivemos opiniões diferentes, com organizações feministas, sobre como criar um conselho de mulheres. Elas começaram a dizer 'elas não querem um conselho de mulheres'. Eu realmente chorei muito naquele momento. Sempre fiz parte do movimento feminista e, naquele momento, fiz parte desse 'elas', daquele Estado que as feministas estavam criticando. Eu realmente chorei muito" (Entrevista com J., membro da Coordenadoria da Mulher, 26 de março de 2006).

Em instituições participativas, burocratas ativistas reutilizam as concepções e os conhecimentos adquiridos durante sua trajetória militante. Isso permite que eles mantenham vínculos com sua rede social e com as ações contenciosas.

Em Recife, a importação de práticas e concepções de ação coletiva tem dois efeitos na condução da conferência. Primeiro, o princípio da não-mixidade em vigor em algumas organizações feministas é aplicado na conferência de mulheres, embora seja controverso no governo local. Essa regra valoriza uma concepção segundo a qual apenas as mulheres devem definir os programas que visam subverter as relações de gênero, porque são elas que experimentam a dominação e que devem ter poder de decisão.

Segundo, molda-se, junto com as participantes feministas, os padrões implícitos de com- portamento esperados dentro da IP, em particular no Conselho Municipal da Mulher, onde se encontram regularmente com as delegadas eleitas durante a primeira rodada de assembléias. Estas são chamadas a reproduzir o "dom de si" que estrutura o ativismo em alguns partidos e organizações da sociedade civil (Lazar, 1998). De fato, além de participar de reuniões mensais, as "conselheiras" são convocadas pelas funcionárias da Coordenadoria da Mulher para organizar ou participar de uma série de ações coletivas. Espera-se que as conselheiras contribuam para a organização de mesas redondas sobre violência contra as mulheres ou marchas de protesto sobre este tema; são convidadas a mobilizar seus vizinhos em diversas outras IPs, como a conferência de saúde ou o orçamento participativo; elas são chamados a participar de reuniões burocráticas. Quando as conselheiras não seguem essa regra implícita e têm uma participação intermitente, estão sujeitas a desaprovação simbólica, de alguma maneira informal e bem humorada, por sua fraca atuação ou até uma chamada pública para que reforce sua função.

O incentivo à mobilização permanente das conselheiras também pode estar ligado à maneira como as funcionárias nomeadas da Coordenadoria da Mulher tentam obter influência dentro do governo local. Elas lidam com uma nova política, mal financiada e pouco institucionalizada. Elas acreditam que a única maneira de alcançar seu objetivo é confiar em uma forte ação coletiva, o que aproxima estes profissionais dos burocratas que atuam em volta do meio ambiente (Abers, 2019) ou da AIDS (Rich, 2019). De fato, de acordo com uma destas funcionárias, a mobilização permanente das participantes deve dar visibilidade às desigualdades de gênero e forçar o governo local a implementar políticas de gênero:

J: Quando você faz parte do governo municipal, fala, fala, mas os outros pensam que o que você diz é um absurdo. Mas quando você tem o apoio da sociedade organizada, mobilizada e diz 'tem que ser assim', é diferente, porque você não está falando sozinha, como uma 'pessoa louca'. É a sociedade pressionan- 
do a prefeitura. Faz uma grande diferença porque, neste caso, não é possível ignorar a questão das mulheres. (Entrevista com J., membro da Coordenadoria da Mulher, 15 de setembro de 2007).

O exemplo da conferência de mulheres em Recife mostra como burocratas militantes moldam a participação pública, conectando-a às práticas e normas da ação coletiva. Nesta perspectiva, a participação não deve ser apenas uma ferramenta para construir programas de políticas públicas, dando voz ao cidadão comum. Deve ter como alvo alguns cidadãos, os excluídos, politizá-los e envolvê-los de maneira duradoura em ações coletivas para mudar a ordem social. De modo semelhante à strong democracy de Benjamin Barber (1984), a participação pública é vista como uma preocupação cotidiana. Portanto, as IPs são significativas não apenas para a definição de políticas públicas, mas também para a esfera militante, como explica a ex-Secretária da Mulher :

K: Quando construímos a conferência de mulheres, pensamos que seria importante incluir mulheres da classe trabalhadora. A fim de pressionar o movimento feminista a discutir com essas mulheres que geralmente estão fora do debate feminista. Pensamos que isso poderia influenciar outras mulheres e que seria útil não apenas para políticas públicas, mas também para o movimento, porque poderia ser reforçado pelas mulheres da classe trabalhadora. Para nós, era importante criar um vínculo com os movimentos populares, para reforçar a agenda e o movimento feminista (Entrevista com K., ex-Secretária da Coordenadoria da Mulher, 8 de junho de 2006).

Essa concepção de participação, que ancora a participação pública na lógica da política contenciosa, difere dos objetivos perseguidos por um segundo tipo de PPP, o profissional da mobilização.

\section{O PROFISSIONAL DA MOBILIZAÇÃO}

O segundo tipo de PPP é chamado de "profissionais da mobilização" porque sua atividade consiste em mobilizar audiências para espaços participativos heterogêneos. Assim como os burocratas militantes, os profissionais de mobilização têm uma trajetória ativista que justifica e explica seu envolvimento na participação dos cidadãos. Mas, a diferença entre eles é que os profissionais da mobilização usam seu conhecimento militante essencialmente para reunir grupos ou organizações e têm um papel secundário durante as assembléias e a definição das normas legítimas dentro dele. O profissional da mobilização geralmente atua em um serviço especializado em democracia participativa. Sua presença é sinal de um maior grau de profissionalização da participação pública nos municípios em que trabalham ou em determinado setor de políticas públicas, do que quando predominam os burocratas militantes. Essa profissionalização tem um efeito paradoxal: embora garanta a presença de vários tipos de grupos sociais, principalmente minorias, também restringe a participação do público a uma gama estável de atores e organizações chamados a participar das IPs. Os membros do setor de democracia participativa em Londrina são ilustrativos desse segundo tipo de profissionais.

\section{Participação pública como atividade per- manente}

Para os profissionais da mobilização, a participação pública é um trabalho permanente. De fato, eles são contratados e pagos para organizar a participação pública. Seu trabalho consiste principalmente em mobilizar audiências e facilitar o debate de diferentes espaços participativos. Esses profissionais são escolhidos por causa de sua trajetória ativista ou participativa durante a qual adquiriram conhecimentos específicos, em particular a capacidade de identificar e mobilizar as redes da sociedade civil. Se estes PPP também podem ter vínculos com um partido político, geralmente isso têm papel secundário em comparação com os burocratas militantes. Sua legitimidade depende mais de seu ativismo em espaços participativos ou organização da sociedade civil do que 
em uma eventual atuação em um partido.

Esse tipo de profissional valoriza outra concepção de participação pública: insiste na necessidade de reunir todos os tipos de atores, mobilizar o maior número de cidadãos e garantir a representação de diversos tipos de grupos e organizações sociais. Sua concepção da participação refere-se à ideia de pluralismo e à expressão das diferentes vozes que compõem o campo social. A missão que eles incorporam é tornar possível a expressão dessas vozes, assegurando uma ampla representação dos atores e incentivando discussões, principalmente quando o público não está familiarizado em falar em público. Esse tipo de profissional vê a participação pública como uma maneira de subverter o viés elitista ou tecnocrático da formulação de políticas e enriquecê-lo pela integração de vários pontos de vista. Essa concepção às vezes pode negligenciar a existência de interesses conflitantes, dependendo dos atores e do tópico discutido.

Esse tipo de PPP pode ser ilustrado pelos membros do "Núcleo de Participação Popular" (NPP) em Londrina. Criada em 2005, este setor do governo local especializado em participação pública faz parte do gabinete do prefeito quando realizo meu trabalho de campo.

O NPP é composto por 12 pessoas, entre as quais quatro nomeados pelo prefeito, encarregados da mobilização da sociedade civil para as reuniões de participação. Os outros realizam operações logísticas e são motoristas, secretários etc. Podemos destacar que em Londrina há menos "cargos de confiança” do que em Recife. Portanto, a nomeação desses PPP, bem como a posição do NPP no topo da hierarquia governamental, comprovam a importância estratégica da participação cidadã.

A criação do NPP é concomitante à multiplicação de conferências municipais para grupos marginalizados, como as conferências de igualdade racial, de deficientes e de jovens. O Núcleo se encarregou de toda a organização dessas três conferências, que não possuíam um setor administrativo na prefeitura. O NPP tam- bém mobilizou o público e facilitou os debates de outras conferências vinculadas a secretarias existentes, como por exemplo a conferência de mulheres. Para entender o perfil dos atores da NPP, podemos nos concentrar em sua principal dirigente.

J. é uma mulher de 43 anos que criou, dez anos antes de nos conhecermos, uma associação de pais e professores em uma zona rural de Londrina. Depois de ser recrutada na escola em que atuava em nome de sua associação, envolveu-se no conselho municipal de saúde de Londrina e tornou-se presidente. Ela então se envolveu no Conselho estadual de saúde e tornou-se novamente presidente do Conselho. Quando o Partido dos Trabalhadores chegou ao poder novamente em 2001, ela foi recomendada por um deputado local para chefiar o NPP.

Embora ela fosse ex-partidária do PMDB, ela ingressou no PT quando começou a trabalhar no NPP. Para ela, trabalhar com participação é: “algo que [ela] já estava fazendo voluntariamente, algo que estava acostumada a fazer e que gostava de fazer”. De fato, para alcançar a presidência de um conselho de saúde, uma das principais IPs locais, os participantes precisam saber como mobilizar o apoio das organizações da sociedade civil e dos delegados que dela participam (Sa Vilas Boas, 2012). Por demonstrar capacidade de mobilizar e reunir grupos e cidadãos ao seu redor ela foi contratada como coordenadora do NPP .

Embora o ativismo leve essas PPP a serem selecionadas, elas não vêem a participação como uma ferramenta para alcançar uma mudança geral da ordem social. Eles preferem entender seu papel como restrito a algumas etapas do processo participativo, em particular a mobilização para reuniões e audiências. Para esse propósito, essas PPP se concentram particularmente em atores tradicionalmente "não ouvidos" (Boullier, 2009), aqueles que geralmente estão ausentes do campo político. Como profissionais de participação pública, eles afirmam "saber" como alcançar esses grupos e como falar com eles. Mas, por valorizar o 
pluralismo, eles também procuram a presença de grupos ou organizações que não são social ou politicamente excluídos, como J. explica:

"J: Quando discutimos a conferência de mulheres, eu disse que não era possível fazer apenas uma assembléia. Porque as pessoas precisam participar. E temos que ir até elas porque, se não, o povo não vem. Então temos que ir à roça (parte rural de Londrina). Eu disse, é impossível não incluir pessoas da roça! Então pensamos em fazer assembléias por regiões e por movimentos: movimento negro, sindicatos, pessoas com deficiência etc. Às vezes pode ser difícil fazer as pessoas entenderem que as coisas precisam ser feitas com democracia. Às vezes é como se ainda estivéssemos sob a ditadura. Algumas pessoas nos mandam fazer isso e aquilo (ela ri). [...] Acho ótimo que M. [a chefe da Secretaria da Mulher] tenha sugerido convidar a ACIL [organização de mulheres empresárias]. Quanto mais você leva as pessoas a participar, mesmo as pessoas com um diploma, melhor é”. (Entrevista com J., Secretária do NPP, 18 de julho de 2007).

Essas PPP concentram-se mais na preparação do que nos objetivos finais da participação pública, porque acreditam que o resultado deve ser definido pelos participantes e no confronto de vários pontos de vista. Durante a conferência em Londrina, quando eles facilitam a discussão, suas intervenções se limitam a explicar os objetivos dados ao dispositivo, iniciando e fomentando a discussão e anotando a proposta das participantes, como podemos ilustrar com um extrato da conferência de mulheres:

A cena se passa na região rural de Londrina, chamada "Guanavera”, nas dependências do centro comunitário. Existem nove mulheres e dois homens. A assembléia faz parte da primeira rodada, durante a qual as participantes são solicitados a fazer propostas sobre políticas locais de gênero. Quando dois membros do NPP chegam, todos estão sentados e aguardam o início da reunião. O primeiro distribui um documento com várias propostas e pede a cada participante que se apresente. Após a apresentação, a líder do centro comunitário, uma mulher chamada Andrea, pergunta ao grupo se alguém quer fazer uma proposta. Uma mulher de 40 anos diz:

- Então, gostaria de dizer que devemos esperar meses para consultar um médico especialista. Por exemplo, tive que esperar seis meses apenas para ver um ginecologista. O dispensário é muito ruim nesse ponto.

Membro do NPP: Gostaria de lembrar que não é uma conferência de saúde.

Andréa: Sim, mas é um problema geral aqui. Temos o direito de realizar um exame médico todos os anos, mas só temos acesso a um ginecologista durante o dia. O que é impossível se você trabalha. Membro do NPP: Você já conversou com o dispensário? Andréa: Isso não muda nada.

O membro do NPP está escrevendo algo que lê: que tal "garantir o acesso ao ginecologista nas áreas rurais”, tudo bem? Várias mulheres dizem que sim. (Diário de campo da autora, 23 de Março de 2007)

De fato, os profissionais de mobilização intervêm menos durante a discussão ou deliberação do que a montante, para organizar o público. Para esse fim, eles aplicam práticas e instrumentos rotineiros para incentivar a participação, seja qual for o tópico ou IP. A conseqüência é um fechamento relativo e paradoxal do público participativo.

\section{Um paradoxal fechamento do público parti- cipativo}

Embora insistam na necessidade de reunir diferentes perfis de atores e organizações, os profissionais de mobilização utilizam formas padronizadas de formar audiências para diferentes tipos de instituições participativas em Londrina. Para todas as conferências municipais, sejam elas sobre saúde, igualdade racial ou mulheres, eles chamam líderes associativos ou de ONGs, colocam folhetos em associações e instituições públicas, como escolas ou hospitais, e enviam cartas individuais a figuras conhecidas, como secretários ou políticos locais. A consequência desse processo rotineiro é que ele acaba favorecendo as organizações em detrimento dos indivíduos. Além disso, eles chamam as mesmas organizações para vários processos participativos. Paradoxalmente, embora os profissionais da mobilização lembrem o quão fortemente comprometidos são com o pluralismo, a maneira como centralizam o processo de mobilização leva ao estreitamento do público. De fato, para ter certeza 
de que nenhum espaço participativo estará vazio, os profissionais de mobilização de Londrina listam os líderes em que podem confiar. Mas, ao mesmo tempo em que garantem que haverá uma audiência, delineiam fortemente sua composição. Esse processo foi observado durante a organização da conferência de mulheres em 2007. O desenho desta última foi confiado ao NPP e baseou-se em dois tipos de assembléias: as territoriais, organizadas nos subúrbios e na zona rural de Londrina; e as "setoriais", com assembléias organizadas, chamadas de "segmentos" da sociedade civil, com representantes de universidades, ONGs, organizações profissionais etc. Mas, sejam regionais ou setoriais, as assembléias costumam reunir os membros de apenas uma ou duas associações e quase nenhuma "mulher comum", ou seja, alguém que ainda não estava envolvido na ação coletiva. Além disso, o "segmento" solicitado a participar era o mesmo, independentemente do tópico discutido. A apresentação que $\mathrm{H}$, membro do NPP, faz de seu trabalho durante uma entrevista que eu fiz com ela é significativa:

"H.: Para conferências de mulheres, fazemos o mesmo que estamos fazendo agora para outras pessoas, como com os idosos [uma conferência de idosos estava ocorrendo quando fizemos a entrevista]. Entramos em contato com associações de bairro ou ONGs. Também enviamos um convite por escrito aos membros do governo.

MH: Quem está encarregado disso?

H.: Eu, J. (chefa da seção), bem... todos os membros do centro. Nós vamos conhecer associações; vamos às escolas locais para explicar o que é uma conferência. Tentamos percorrer a cidade inteira. Em geral, damos às pessoas um documento para que elas possam ter todas as informações.

MH: Durante a última assembléia (das conferências de mulheres), tive a impressão de que você conhecia quase todo mundo ...

H .: Sim... porque conheço Laura, que é a presidente da creche. Liguei para ela e pedi-lhe para trazer todos os amigos, vizinhos e todas as mulheres com quem ela está em contato. Também entrei em contato com membros do Partido [dos Trabalhadores]. Então é assim que fazemos. Para os deficientes, chamamos Martine, porque ela é uma grande representante. Para os negros, chamamos Eugenia e ela traz todo mundo. Laura também é negra, mas não liga apenas para negros." (Entrevista com H,, Membro do NPP, 17 de Julho de 2007).

O processo de fechamento do campo participativo pode ser entendido como resultado da personalização do "segmento" da sociedade civil. Como os membros do NPP confiam nos líderes organizacionais que já identificaram e sabem que garantirão a mobilização do grupo-alvo, o NPP capacita alguns líderes sobre outros no campo participativo, chamando-os a participar de todas as conferências. Portanto, podemos nos perguntar se o posicionamento múltiplo de alguns líderes comunitários ou associativos em IPs (Romão, 2010; Sa Vilas Boas, 2012) não é apenas o resultado das práticas dos participantes, mas também de algumas estratégias do NPP para “construir" audiências.

Portanto, o profissional da mobilização pode ter um efeito ambivalente na participação pública. Sua existência demonstra um nível mais profundo de profissionalização da participação público. Mas esse processo não leva necessariamente a uma participação mais ampla dos cidadãos. Como ilustra o caso de Londrina, a rotinização de suas atividades acompanha uma relativa estabilização dos parceiros que eles convidam para fazer parte do público.

Esse PPP pode ser visto como um perfil intermediário entre os burocratas militantes, cuja ação é inspirada na esfera ativista, e o especialista em participação pública, que agora vamos estudar.

\section{OS ESPECIALISTAS EM PARTICIPA- ÇÃO PÚBLICA}

Os especialistas em participação pública diferem dos outros dois tipos de profissionais públicos, porque sua legitimidade e vontade de organizar e facilitar dispositivos participativos não dependem de um experiência como ativista ou de uma trajetória participativa. Baseia-se, antes, em conhecimentos especializados que podem ser técnicos, burocráticos ou 
acadêmicos. Esse tipo de PPP contribui para o aprimoramento técnico de instituições participativas. Eles não são necessariamente burocratas do governo local, pois podem agir externamente, por meio de contratos, para desenvolver uma parte das atividades de um conselho ou outra IP. Esse terceiro tipo é particularmente heterogêneo, pois inclui especialistas em serviços digitais ou comunicação que ampliaram sua influência no campo participativo (Bherer; Gauthier; Simard, 2017). Alguns dos atores responsáveis pelo Orçamento Participativo Digital (e-Op) em Belo Horizonte ilustram esse terceiro tipo.

\section{O crescimento da especialização no campo participativo}

Vimos que burocratas militantes importam concepção e normas de ação coletiva no campo participativo, enquanto os profissionais da mobilização utilizam meios rotineiros para mobilizar atores e grupos. Nos dois casos, eles justificam sua ação por conhecimento e know-how que não são técnicos nem altamente especializados, mas confiam nas habilidades aprendidas nas organizações da sociedade civil ou nos dispositivos participativos. O terceiro tipo de PPP analisado aqui tem um perfil diferente. Sua integração no campo participativo depende do domínio de uma perícia, definida จิ como uma competência específica, cientificamente ou tecnicamente (Delmas, 2011, p. 9).

ticipativo é significativo em Belo Horizonte, $\rightarrow$ uma cidade que experimentou vários tipos $\dot{2}$ de instituições participativas, como o conheले cido Orçamento Participativo (OP) criado em 1994, um Orçamento Participativo Habitacional (OPH) construído em 1995 e, desde 2006, um Orçamento Participativo Digital (e-OP). Devido à institucionalização de diferentes dispositivos conhecidos, Belo Horizonte é, talvez mais do que as outras cidades estudadas neste artigo, caracterizada pela coexistência de di- ferentes tipos de PPP. No entanto, vamos nos concentrar principalmente no terceiro tipo, ou seja, nos especialistas em participação pública.

O surgimento desse terceiro tipo de PPP em Belo Horizonte está ligado à evolução das relações de poder no governo local e, por extensão, no campo participativo. Montenegro (2011) analisa a evolução das concepções de democracia participativa devido à evolução da relação de poder entre dois grupos da administração pública de Belo Horizonte, de 1994 a 2000. O primeiro, organizado em torno do prefeito do PT eleito em 1994, Patrus Ananias, define a participação na linha direta do "modo petista de governar" e do pensamento social católico. Considera a participação como a inclusão da classe trabalhadora e dos pobres na definição e no controle da ação pública. Ele inspirou o desenho do OP e do OPH. Um segundo grupo, representado pelo secretário de planejamento, Mauricio Borges, é composto por acadêmicos e especialistas, oriundos de um centro especializado em planejamento regional (CEDEPLAR) e com habilidades técnicas em políticas urbanas. Esse grupo promove uma concepção mais "técnico-política” da elaboração de políticas públicas (Montenegro, 2011, p. 156-157).

Pouco a pouco, esta concepção torna-se central no governo local, especialmente após a eleição do prefeito Fernando Pimentel em 2000. Pimentel é economista e ocupou o cargo de Secretário de planejamento nos anos 1990. Ele ajuda a promover o grupo de especialistas em economia e planejamento urbano, dando-lhes posições-chave no município. E também foi no seu mandato que ferramentas digitais passaram a ser usadas para aprimorar a participação cidadã, levando à criação do e-OP. Um novo perfil de PPP emerge progressivamente em torno deste dispositivo, escolhido por seu conhecimento acadêmico ou técnico.

De fato, a seleção dos PPP responsável pelo e-OP depende da proximidade pessoal e acadêmica da rede de especialistas que governa a cidade de Belo Horizonte a partir de 2000. A legitimidade desse terceiro tipo de PPP não 
se baseia em uma trajetória militante ou participativa, mas em seus conhecimentos acadêmicos e em pertencer a uma rede específica de especialistas. Dois exemplos ilustram o perfil dos especialistas em participação pública. O primeiro é a Subsecretária de planejamento, que desempenhou um papel central no monitoramento do e-OP de 2006 a 2010. Ela explica sua nomeação como subsecretária de planejamento da seguinte maneira:

"A: Eu nunca fui ativista do PT. Eu era uma eleitora de esquerda, sempre votei nos partidos de esquerda. $\mathrm{E}$ as pessoas no poder na época eram meus professores universitários. Eu tive uma trajetória universitária normal. Mas eu trabalhei com eles e acho que eles estimavam o meu trabalho. Eu também era funcionária pública municipal. Então, quando fui nomeada para a Secretaria de Planejamento, o Secretário tinha sido meu professor e orientador de mestrado. Porque naquela época havia muitos professores e nos conhecíamos do mundo acadêmico" (Entrevista com A., ex-Subsecretária do planejamento, 10 de outubro de 2014).

O segundo exemplo é a gerente de projeto do e-OP em 2014. Esta mulher de 38 anos, doutoranda com tese sobre democracia participativa, também enfatiza sua trajetória acadêmica e as relações pessoais que teve com alguns especialistas para explicar como ela foi escolhida para sua posição na prefeitura:

"D: Havia uma pessoa da Secretaria de planejamento. Ele me conhecia e eles precisavam de alguém. Por que eu? Por ter feito meu mestrado em monocultura de eucalipto me envolvi em vários debates e redes de ONGs [...]. Estudei com a pessoa que indicou meu nome e imagino que ele pensava que, devido à minha experiência, eu tinha o perfil para organizar este trabalho, criar conteúdo para o OP Digital” (Entrevista com D., ex-gerente do e-OP, 16 de outubro de 2014).

Os dois exemplos dados aqui são burocratas que atuam na administração local, tal como os PPP estudados no Recife e Londrina. Mas, a criação desta nova ferramenta, o e-OP, também gera as condições para a contratação de trabalhadores externos, mais precisamente, uma empresa especializada em comunicação, responsável pela criação da arquitetura e do desenho do site. Selecionada por meio de uma licitação, essa empresa também ilustra a mudança progressiva das habilidades esperadas no campo da participação pública para trazer o público à participação. De fato, a contratação de uma empresa, que atua em conjunto com o serviço de tecnologia de informação (TI) da Prefeitura, é justificada pelo conhecimento especializado em webdesign que possui, uma estratégia para atrair novos públicos não familiarizados com a democracia participativa. Como explica a ex-Subsecretária de planejamento:

A: Para a primeira edição do OP Digital, o serviço de TI fez o site. Mas em 2008, contratamos uma empresa porque queríamos obter mais ferramentas de discussão online, um site mais interativo. [...] Não foi realmente uma ruptura, no sentido de que, pela primeira vez, teria sido desenvolvido internamente e pela segunda vez externamente. O serviço municipal de TI ainda estava envolvido no processo em 2008. Mas queríamos outro tipo de desenvolvedor, que traria uma experiência que o serviço de TI do município não tem... para criar ferramentas para estimular debates online, para que o site seja mais interativo, mais fácil de gerenciar (Entrevista com A., ex-Subsecretária do planejamento, 10 de outubro de 2014).

Em paralelo, ocorre o aparecimento de novos profissionais especialistas em participação, enquanto as concepções de democracia participativa evoluem. De fato, esses PPP favorecem uma mudança no público esperado e o papel que lhes é atribuído.

\section{Incluindo todos os indivíduos para expres- sar uma voz}

Em Belo Horizonte, a criação de um Orçamento Participativo Digital é interessante para entender como o processo de aprimoramento de habilidades dos PPP acompanha a evolução das concepções de democracia participativa. Mais precisamente, em Belo Horizonte e em Londrina, a profissionalização do campo acompanha a vontade de ampliar o público chamado 
a participar. Mas, em Belo Horizonte, esse alargamento segue uma concepção mais individual de participação, que não se concentra mais em grupos, sejam definidos como "excluídos", "minoritários" ou "representativos de determinado segmento" etc., mas em "cidadãos".

Primeiro, vale lembrar que na cidade coexistem diferentes concepções de democracia participativa e que apenas focaremos em uma delas, desenvolvida por alguns especialistas em participação pública. De fato, em Belo Horizonte e em muitas outras cidades onde um OP foi criado, a ambição inicial era "incluir os excluídos”, ou seja, atores geralmente sub-representados no campo político por causa das desigualdades sociais. As instituições participativas, e mais especificamente o OP, foram usadas como uma ferramenta que poderia mudar a ordem social e política, dando voz a grupos que geralmente têm pouca influência na esfera política. Em Belo Horizonte, essa concepção ainda orienta a ação de alguns PPP, principalmente em torno do OP e do $\mathrm{OPH}$.

$\mathrm{O}$ e-OP, à primeira vista, é coerente com essa concepção. Seu ponto de partida é uma análise crítica dos espaços presenciais de participação, porque estes são vistos como atrativos aos cidadãos já engajados e não aos cidadãos “comuns". Segundo o prefeito Pimentel:

O OP tradicional [...] atinge pessoas já mobilizadas, essa e a verdade. Ele atinge as pessoas que já se mobilizam para reuniões de associações de bairros, para reuniões de atividades associativas em geral, ONGs ou partidos políticos, não é, ou clubes recreativos isso é muito pouco -, mas, enfim, pessoas que já tem esta disponibilidade. Então, poderia se dizer que ele só mobiliza militantes, strito senso. Não, não é verdade! Ele vai alem do militante propriamente dito, mas ele não chega naquela parcela da população - vamos chamar de cidadão comum - que tem dificuldades, seja dificuldade de tempo, seja porque tem dificuldade motivacional de participar de três, quatro, cinco reuniões (Pimentel apud Lana, 2011, p. 229).

O uso de ferramentas digitais deve, portanto, seguir a promessa inicial da democracia participativa e ajudar a "abrir" um campo participativo que acabou sendo "capturado" por um perfil de cidadãos já interessados em política. E, além desse objetivo geral, a ambição é também atrair novos públicos. Enquanto a maioria das experiências de OP buscam agregar pessoas de baixa renda, o e-OP tem como objetivo atrair grupos geralmente ausentes das IPs tradicionais, mas não necessariamente desprovidos de recursos políticos. Espera-se que dois grupos participem online: a classe média e os jovens. Como explica a chefe da Secretaria Municipal de Gestão Compartilhada, responsável pelas IPs locais:

Quando o OP Digital foi criado... eu não estava lá naquele momento, mas sei que a ideia era que a democracia participativa tem um custo. E nem todo mundo está disponível ou está interessado em participar. O OP regional é composto principalmente de pessoas pobres porque elas precisam melhorar seu padrão de vida. E a classe média ... mesmo sendo confrontada com a segurança pública... ela tem muito mais infraestrutura. Portanto, quando você junta pessoas pobres e a classe média, a diferença pode ser enorme. O segundo pode se sentir envergonhado, porque eles vêm de um bairro rico. Quando participam de um debate sobre saneamento, pensam: "Estou aqui para discutir isso?". Então pode ser difícil misturar projetos e pessoas (Reunião coletiva, 13 de outubro de 2014).

Por não supor um confronto direto, a web deve permitir um diálogo entre atores com recursos diferentes, para definir projetos para "toda a cidade" e não apenas para grupos específicos dentro dela. Nesta perspectiva, o e-OP é visto como um novo estágio da democracia participativa que rompe com a síndrome $\mathrm{NIMBY}^{3}$ e ajuda a mudar a escala da discussão. A deliberação é fomentada na escala da cidade. Portanto, a definição de projetos legítimos para toda a cidade deve incluir todos os grupos sociais e não apenas os mais pobres. De acordo com a ex-Subsecretária de planejamento:

A: Um dos objetivos era fomentar uma discussão sobre a cidade como um todo. Porque o OP regional ...

${ }^{3}$ Acrônimo que em língua inglesa significa "Not In My BackYard" e que caracteriza pessoas que não admitem que algo desagradável ou potencialmente agressivo seja instalado em sua vizinhança, mas não se opỗe a que isso ocorra em outro lugar da cidade. 
e quero deixar claro que é perfeitamente legítimo ... concentra-se no local em que moro: minha rua, meu bairro, a escola do meu filho. Mas pensamos que era importante combinar esse olhar local com um olhar para toda a cidade. O lugar onde circulo, o impacto que isso tem na cidade. Por isso, pensamos que um projeto mais amplo poderia ser combinado com esse olhar local (Entrevista com A., ex-Subsecretária do planejamento, 10 de Outubro de 2014).

Como os profissionais da mobilização, os especialistas em participação pública querem garantir a expressão do maior número possível de atores. Mas enquanto o primeiro se concentra em grupos organizados, o segundo quer ouvir a voz de todos, concebida de maneira mais individualizada.

De fato, a participação digital é vista como uma ferramenta que resolve os dilemas da ação coletiva, diminuindo o custo da participação: como o cidadão pode dar seu ponto de vista de casa, em "dois cliques", espera-se uma redefinição do perfil habitual do participante. Certamente, os PPP estão cientes das desigualdades digitais no espaço social e dos riscos de excluir pessoas pobres ao usar a ferramenta digital. Por isso, o município fornece computadores com acesso à internet no bairro de baixa renda durante cada edição do OP, por meio de um ônibus itinerante. Mas se o dispositivo digital é organizado para incluir cidadãos ricos e pobres, ele se baseia em uma concepção específica do que deve ser a participação. Assim, a participação digital é vista como a expressão da voz de todo cidadão, mas sem implicar um compromisso duradouro. É considerado principalmente como um "ato de votação" para escolher entre diferentes proposições (Sa Vilas Boas; Sampaio, 2018). Portanto, a participação digital não implica necessariamente em um compromisso maior com o processo participativo, pelo contrário, deve fornecer a opção ao cidadão em uma forma mais pontual de participação. Diferentemente dos burocratas militantes, esse PPP não vê necessariamente a participação do cidadão como um prelúdio ou uma ferramenta educativa para a ação coletiva.

No OP Digital, o participante legítimo não é um indivíduo que deve ser politizado para reforçar a ação coletiva, mas alguém que expressa pontualmente uma opinião em debates públicos.

\section{CONCLUSÃO}

Este artigo estudou os atores que organizam, implementam e facilitam as IPs para compreender como suas práticas molda os espaços participativos. A partir da análise da trajetória desses profissionais e das lógicas institucionais que guiam a sua ação, destacamos três tipos de PPP, cuja concepção do que é participar e do público legítimo difere.

O primeiro, o burocrata militante, tende a pensar a organização das IPs sob o ângulo da ação coletiva. Selecionado em razão da sua trajetória militante, o ativismo orienta a compreensão que ele tem da participação cidadã. Favorece a presença de um público que representa ou pode apoiar a causa defendida no aparato estatal, buscando a mudança social e política. A participação é então vista como um recurso para reforçar a sua própria administração, mas também as organizações da sociedade civil parceiras.

O segundo tipo, o profissional da mobilização, pensa e organiza a participação cidadã sob o ângulo da pluralidade democrática. Geralmente selecionado por sua capacidade de mobilização, adquirida numa trajetória caracterizada por um envolvimento em IPs ou em organizações da sociedade civil, ele busca assegurar a presença de uma audiência diversificada. Para esse objetivo, usa técnicas e saberes comprovados em várias IPs, o que leva paradoxalmente ao encerramento dos processos participativos em torno de alguns tipo de atores, principalmente organizações.

O terceiro tipo de PPP, o especialista em participação pública, concebe a participação sob o ângulo técnico. Selecionado pelos conhecimentos especializados que ele tem, este PPP tenta inovar usando novas técnicas ou 
visando outros públicos do que os excluídos. Particularmente heterogêneo, este terceiro tipo pode, ou não, ligar a participação a um projeto de mudança social. Quando é o caso, não acredita que essa mudança depende necessariamente da mobilização da sociedade civil. Em todos os casos, as IPs são tecnicizidas sob a sua influência.

A análise desses tipos-ideais nos permite levantar duas perguntas conclusivas para pensar as mudanças da participação cidadã no Brasil. Primeiro, seria interessante pesquisar qual é a proporção e a evolução entre estes três tipos com o processos de difusão das instituições participativas no Brasil e o retrocesso desde alguns anos. Segundo, na linha dos estudos sobre os PPP, seria heurístico questionar os aspectos materiais e financeiros da participação cidadã. Este campo se tornou um "mercado" no Brasil? Que organizações, grupos ou atores vivem de e para a participação cidadã? Dito de outra forma, podemos observar, no Brasil, um processo de profissionalização comparável ao que foi analisado na América do Norte e na Europa? Estas são questões que podem orientar novas pesquisas no campo de estudos sobre participação pública no Brasil.

Recebido para publicação em 29 de novembro de 2019 Aceito em 29 de maio de 2020

\section{REFERÊNCIAS}

ABERS, R. Ativismo na burocracia? O médio escalão do Programa Bolsa Verde. In: CAVALCANTE, P.; LOTTA,

@ G. (Org) Burocracia de médio escalão: perfil, trajetória e atuação. Brasília: ENAP, p. 143-176, 2015.

$\dot{2}$ ABERS, R. Bureaucratic Activism: Pursuing की Environmentalism Inside the Brazilian State, Latin $\therefore$ American politics and society, v. 61, p. 21-44, 2019.

AVRITZER, L. Participatory Institutions in Democratic Brazil. Washington: Woodrow Wilson Centre Press, 2009.

AVRITZER, L. NAVARRO, Z. A Inovação democrática no Brasil. São Paulo: Cortez Editora, 2003.

BARBER, B. Strong Democracy: Participatory Politics for a New Age. Berkeley: University of California Press, 1984.

BECKER, H. The Nature of a Profession. In: HENRY N. B. (Org.) Education for the Professions: The $61^{\text {st }}$ Yearbook of the National Society for the Study of Education, Chicago: University of Chicago Press, 1962, p. 24-46.

BHERER, L.; GAUTHIER, M.; SIMARD, L. (Org.). The professionalization of public participation. New York: Routledge, 2017a.

BHERER, L.; GAUTHIER, M.; SIMARD, L.(Org.) Who's the client? The Sponsor, Citizens, or the Participation Process? Tensions in the Quebec (Canada) Public Participation field. In: BHERER, L.; GAUTHIER, M.; SIMARD, L.(Org.) The professionalization of public participation. New York: Routledge, 2017b, p. 115-138.

BORBA, J.; LUCHMANN, L. H. Orçamento participativo. Análise das experiências desenvolvidas em Santa Catarina. Florianópolis, Editora Insular, 2007.

BOULLIER, D. Choses du public et choses du politique. Pour une anthropologie des inouïs. In: CARREL, M.; NEVEU, C.; ION, J. (Org.) Les intermittences de la démocratie. Formes d'action et visibilité citoyenne dans la ville. Paris: L’Harmattan, 2009, p. 21-39.

BOUSSARD, V. et al. (Org.). L'injonction au professionnalisme. Analyses d'une dynamique plurielle. Rennes: Presses universitaires de Rennes, coll. Des Sociétés, 2010.

CHAPOULIE, J.M. Sur l'analyse sociologique des groupes professionnels. Revue Française de sociologie, v. 14, p. 86114, 1973.

DELMAS, C. Sociologie politique de l'expertise. Paris: La Découverte, 2011.

DEMAZIERE, D. Professionnalisations problématiques et problématiques de la professionnalisation : postface. Formation Emploi. Revue française de sciences sociales, n¹09, p. 83-90, 2009.

DEMAZIERE, D.; GARDEA, Ch. Introduction. In (Org.) Sociologie des groupes professionnels. Acquis récents et nouveaux défis. Paris: La Découverte, 2009, p. 13-24.

ESCOBAR, O. Making it Official: Participation Professionals and the challenge of Institutionalizing Deliberative Democracy. In: BHERER, L.; GAUTHIER, M.; SIMARD, L. (Org.) The professionalization of public participation. New York: Routledge, 2017, p. 141-164.

GAXIE, D. Les enjeux citoyens de la professionnalisation politique. Mouvements, v. 18, n. 5, p. 21-27, 2001.

JEANNOT, G. Les métiers flous du développement rural. Sociologie du Travail, v. 47, n. 1, p.17-35, 2005.

LANA, M. Governança democrática e incorporação das novas tecnologias de comunicação e informação: a experiencia do Orçamento Participativo Digital de Belo Horizonte. 2011, 245 p. Dissertação (Mestrado em Ciências Politica).Programa de Pós-graduação em Ciências Sociais da Universidade Federal de Minas Gerais.

LAZAR, M. Le parti politique et le don de soi. Vingtième siècle, n. 60, p. 35-42, 1998.

LEE, C. W. Do-it-Yourself Democracy: The Rise of the Public Engagement Industry. Oxford: Oxford University Press, 2015.

LEE, C. "Public participation Professionals in the US: Confronting Challenged of Equity and Empowerment". In: BHERER L., GAUTHIER M. \& SIMARD L. (Org.) The professionalization of public participation. New York: Routledge, 2017, p. 65-86.

LEE, C.; ROMANO, Z. Democracy's New Discipline: Public Deliberation as Organizational Strategy. Organization Studies, vol. 34, n5-6, p. 733-753, 2013.

MAZEAUD, A.; NONJON, M. Le Marché de la démocratie participative. Vulaines-sur-Seine : Le Croquant, 2018.

MICHON, S.; OLLION,É., Retour sur la professionnalisation politique. Revue de littérature critique et perspectives. 
Sociologie du travail [En ligne], v. 60 , n. 1, 2018, Disponível em: http://journals.openedition.org/sdt/1706; DOI: 10.4000/sdt.1706, Acesso em: 03.04.2019

MONTENEGRO, A. Planejamento, participação social e reformas administrativas: a experiência da prefeitura de Belo Horizonte nos 16 anos de governo democrático popular, 2011, 252 p. Tese (Doutorado em Ciências Politica). Programa de Pós-graduação em Ciências Sociais da Pontifícia Universidade Católica de Minas Gerais.

REIS, E. T. Dos. Apropriações da gramática democrática, perfis militantes e concepções de gestão pública (RS e MA). In: MARENCO A. (Org.) Os Eleitos. Representação e carreiras políticas em democracias, 1ed. Porto Alegre: Editora da UFRGS, 2013, p. 53-77.

REVEL, C. et al. (Org.). Le débat public: une expérience française de démocratie participative. La Découverte, 2007.

RICH, J. State-Sponsored Activism: Bureaucrats and Social Movements in Democratic Brazil. New York/ Cambridge: Cambridge University Press, 2019a.

RICH, J. Making National Participatory Institutions Work: Bureaucrats, Activists, and AIDS Policy in Brazil. Latin American Politics and Society, n. 61, v. 2, p. 45-67, 2019b.

ROMÃO, W. de Melo, Nas franjas da sociedade política: estudo sobre o orçamento participativo, 2010, 235p. Tese (Doutorado em Sociologia). Programa de Pós-graduação em Sociologia da Universidade de São Paulo.
SA VILAS BOAS, M-H. Du quartier à l'Etat. Sociologie des publics des dispositifs participatifs brésiliens. Le cas des conférences des femmes de Recife et de Londrina (Brésil). 2012, 495, Tese (Doutorado em Ciência Politica), Programme de troisième Cycle de l'Institut d'Etudes Politiques d'Aix-en-Provence.

SA VILAS BOAS, M-H. Los efectos de la participacion cuidadana desde uma perspectiva relacional. El caso de las conferencias de mujeres de Recife y Londrina (Brasil). In: DABENE, O.; LAUNAY, C.(Org.) Les efectos de los procesos participativos en la acción pública, Buenos Aires: Editorial Teseo/ OPALC, 2019, pp. 50-68.

SA VILAS BOAS, M-H.; SAMPAIO, R. Figures de la citoyenneté dans le budget participatif numérique de Belo Horizonte. In : DE BIASE, A. ; OTTOVIANO, N. ; ZAZA,

O. (Org.) Digital Polis. La ville face au numérique : enjeux d'un projet conjugué au futur, Paris, ed. Oeil d’Or, 2018, p. 71-86.

SOUZA, C. H. L. ; PIRES, R, Conferências nacionais como interfaces socioestatais: seus usos e papéis na perspectiva dos gestores federais. Revista do Serviço Público (RSP), Brasília, v. 63, p. 499-518, 2012. 


\section{IMPLEMENTING PUBLIC PARTICIPATION IN BRAZIL: a sociology of secondary actors}

\section{METTRE EN OEUVRE LA PARTICIPATION PUBLIQUE AU BRESIL: Sociologie d'acteurs secondaires}

\author{
Marie-Hélène Sa Vilas Boas
}

Participatory devices in Brazil have been analyzed in a dense literature examining the ambivalent projects pursued through citizen participation, the involvement of citizens in these projects and their varying effects on public policy or the political sphere. What is lacking is an in-depth analysis of the role of public participation professionals (PPP) in Brazil, namely, the specific actors who are paid to design, implement or facilitate participatory forums. This article uses a qualitative methodology to develop a typology of organizers of some Brazilian participatory mechanisms, by studying their trajectory and conceptions of participation they support. Its aim is to show that these actors are central in defining how citizens should participate and who is part of the legitimate audience. Therefore, PPPs play a major role in reinforcing the transformative scope of a device or, on the contrary, in limiting it to a simple consultation of citizens, through the audience rallied, the tool(s) they choose or the meaning they give to participation.

KeYwords: Public participation professional. Mots-CLÉs:Démocratieparticipative.Professionnalisation. Participatory democracy. Professionalization.Brazil. Brésil. Analyse comparative.

Typology. Comparative analysis.
Les dispositifs participatifs brésiliens ont été analysés par une vaste littérature qui a mis en évidence la diversité des projets poursuivis, les motifs de l'engagement des citoyens et les effets de la participation sur le champ politique. Toutefois, peu de travaux interrogent le rôle joué par les professionnels de la participation, c'est-à-dire les d'acteurs qui définissent, mettent en œuvre et facilitent les assemblées participatives. Cet article présente une typologie des organisateurs de la démocratie participative au Brésil, en se fondant sur une méthodologie qualitative. Il montre que ces acteurs secondaires qui traduisent et mettent en œuvre les projets définis par les élus jouent un rôle de premier plan dans la délimitation de ce que participer veut dire et des publics légitimes. En privilégiant certains comportements, certains outils ou certains acteurs, ces professionnels peuvent renforcer la portée transformatrice des dispositifs participatifs ou au contraire, les restreindre à de simples outils de communication institutionnels.

Marie-Hélène Sa Vilas Boas - Doutora em Ciência Politica pelo Instituto de Estudos Políticos d'Aix-enProvence. Professora do Departamento de Ciência Política da Universidade Côte d'Azur. Coordenadora do Programa de mestrado em Ciência Política da Universidade Côte d’Azur. Integra o Laborátorio ERMES, desenvolvendo pesquisas na área da participação política no Brasil. Suas mais recentes publicações são: A participação popular na Assembleia Constituinte: confrontos discursivos sobre um conceito politico. Estudos ibero-americanos, (v. 44, $\mathrm{n}^{\circ} 2$ 2, 2018); The genesis of participatory democracy in Brazil: a scientific (re)construction. Brazilian Political Science Review (v. 11, $\mathrm{n}^{\circ} 1$, 2017). 